\title{
O ESPAÇO EUROPEU DE ENSINO SUPERIOR PARA UMA NOVA
} ORDEM EDUCACIONAL?

\section{Fátima Antunes}

\section{RESUMO}

O Processo de Bolonha constitui um método de acção política em direcção ao Espaço Europeu do Ensino Superior que representa uma nova ordem das relações sociais em educação. A governação multi-escalar, a acção transnacional, a agenda globalmente estruturada para a educação e modelo(s) educativo(s) de ambição mundial perfilam o terreno em que se confrontam programas e protagonistas em torno da constitucionalização do projecto neoliberal e da construção da educação como direito humano ou mercadoria. Neste contexto, o Processo de Bolonha está a configurar um novo quadro regulatório para o ensino superior na Europa em que o mercado ou o cosmopolitismo são sentidos possíveis da mudança com desiguais probabilidades de desenhar o futuro.

\section{PALAVRAS-CHAVE}

Processo de Bolonha; Espaço europeu de ensino superior; Regulação do ensino superior; Governação da educação

\section{THE EUROPEAN HIGHER EDUCATION AREA TOWARD A NEW EDUCATIONAL ORDER?}

\begin{abstract}
Bologna Process constitutes a method of political action toward the European Higher Education Area that represents a new ordering of social relationships in education. Multi-scalar governance, transnational action, a globally structured educational agenda and world ambitious educational models fabricate the terrain where programs and protagonist around the constitutionalization of the neoliberal project and the construction of education as a human right or as a merchandise. In this context, Bologna Process delineates a new regulatory framework for Higher Education in Europe where the market or cosmopolitanism are possible meanings and directions of change with unbalanced probabilities of benchmarking future.
\end{abstract}

\section{KEYWORDS}

Bologna process; European higher educational area; Higher education regulation; Education governance 


\section{INTRODUÇÃO}

O Espaço Europeu de Ensino Superior (EEES) é hoje uma nebulosa que bem sugere as dramáticas transformações do campo da educação. A expressão nova ordem educacional é ainda, na sua relativa opacidade e pluralidade de sentidos, uma âncora no esforço de compreensão das novas realidades. Se o EEES nasceu como programa político publicamente anunciado em 1998, aquela última expressão surgiu também com o novo século enquanto tentativa de leitura articulada e crítica das miríades de movimentos que revoluciona(va)m o terreno educativo (FIELD, 2000; LAVAL; WEBER, 2002).

A União Europeia e o continente Europeu são os espaços sócio-geográficos que estudamos e que orientam e alimentam os nossos esforços analíticos e empíricos, ainda que as dinâmicas mais marcantes estejam longe de constituir um exclusivo desta região do mundo. Em todo o caso, o EEES, como a União Européia, são inovações particularmente desenvolvidas de tendências mais globais, ainda que não uniformes, mesmo quando hegemônicas.

O EEES constitui o horizonte emblemático de um programa político lançado, de forma mais ou menos discreta, em 1998 por quatro países líderes da União Européia e de modo mais retumbante em 1999 em Bolonha: o conhecido Processo de Bolonha, hoje abrangendo mais de quarenta países europeus, foi publicamente anunciado através da Declaração do mesmo nome subscrita já então por vinte e nove países europeus. A agenda apresentada percorria seis áreas de atuação, posteriormente alargadas para dez, e o método de desenvolvimento da mesma apontava para o que viria a configurar-se como um importante instrumento de coordenação e de europeização de políticas (públicas) educativas: os processos ${ }^{1}$.

\footnotetext{
${ }^{1}$ Os processos têm sido usados como instrumentos/métodos de regulação (harmonização) supranacional de políticas nacionais, frequentemente em áreas em que a União Europeia detém uma competência apenas subsidiária (e não específica), mas em que se pretende obter mudanças profundas, convergentes e articuladas. São exemplos conhecidos os domínios do emprego e da educação. Em diversos casos, tem sido lançada mão daquele recurso cujos resultados são expressivos, com custos negligenciáveis do ponto de vista da legitimação dos Estados que protagonizam as mudanças. Isto acontece devido à conjugação de um conjunto de condições: (i) a débil institucionalização e informalidade das instâncias deliberativas dispensa os debates, as consultas ou autorizações devidas dos órgãos nacionais; (ii) aos governos e actores nacionais e no terreno é atribuída a missão de encontrar os meios para cumprir as metas fixadas; (iii) é possível evocar o (mesmo que, em rigor, inexistente) mandato supranacional para justificar as medidas tomadas; (iv) facilita a repetição e o abuso de situações de política de facto consumado. São, assim, inúmeros e evidentes os ganhos de legitimação ou, pelo menos, de favorecimento da evasão à responsabilidade face às populações ou segmentos visados, por parte das instâncias governativas: a Comissão ou o Conselho Europeus ou a Conferência Ministerial não têm rosto ou não respondem perante a população; o governo nacional e os responsáveis políticos da tutela podem escudar-se nas instâncias e deliberações supranacionais e transferir o ónus da concretização destas para as entidades no terreno; o rosto do sistema e das decisões tomadas são os profissionais que as executam. Assim acontece, por exemplo, com o Processo de Bolonha em que o descontentamento dos estudantes se expressa, em primeiro lugar e quase exclusivamente, perante as instituições em que experimentam as medidas políticas e os órgãos e docentes que as veiculam e executam.
} 
As linhas de acção definidas para o Processo de Bolonha são as seguintes: 1Adopção de um sistema de graus facilmente legível e comparável; 2- Adopção de um sistema essencialmente baseado em dois ciclos; 3- Estabelecimento de um sistema de créditos; 4Promoção de mobilidade; 5- Promoção da cooperação Europeia na garantia de qualidade; 6Promoção da dimensão Europeia no ensino superior; 7- Aprendizagem ao longo da vida; 8Instituições do Ensino Superior e Estudantes; 9- Promover a atractividade do Espaço Europeu de Ensino Superior; 10- Estudos de doutoramento e a sinergia entre o Espaço Europeu de Ensino Superior e o Espaço Europeu de Investigação.

No campo da educação, os Processos de Bolonha e de Copenhaga ${ }^{2}$, em particular o primeiro, inauguraram uma fase e constituem uma modalidade inédita na regulação supranacional da educação: por um lado, o seu âmbito geográfico-político tende a assumir contornos continentais; por outro lado, a sua configuração organizacional é a de uma plataforma intergovernamental - a Conferência Ministerial -, com uma institucionalização mínima, sem estruturas fixas pré-definidas, assentando em grupos de seguimento e de coordenação formados em cada Conferência Ministerial e em diversos grupos de trabalho temáticos.

Encontramo-nos, assim, com esta nova abordagem dos Processos, perante uma dinâmica radicalmente nova de mudança educacional e de elaboração de políticas educativas, em que os governos definem e assumem compromissos políticos em fóruns supranacionais constituídos para o efeito que são posteriormente ratificados pelas instituições nacionais e em que o carácter voluntário, formalmente não vinculativo, da adesão legitima a ausência de processos institucionalizados e estruturados de debate, negociação e construção de consensos nacionais prévios aos compromissos assumidos acerca das mudanças propostas. De facto, as decisões tomadas nas Conferências Ministeriais são transpostas para os sistemas educativos nacionais, constituindo um expedito processo de alteração das estruturas, peça a peça, dando corpo ao programa definido ao nível supranacional.

Como se percebe, o desígnio foi, desde o início, o de abranger um espaço sóciopolítico bem mais amplo do que a União Europeia, ainda que este bloco regional e os seus órgãos políticos tenham assumido papéis-pivot determinantes, com, por exemplo, a Comissão

\footnotetext{
${ }^{2} \mathrm{O}$ chamado Processo de Copenhaga reúne mais de trinta países europeus, cujos governos assumem compromissos políticos com o fim de tornar permutáveis e reconhecidos os percursos e as aprendizagens, no âmbito do ensino e formação profissionais, efectuados em qualquer dos estados envolvidos (cf. Copenhagen Declaration, 2002).
} 
Europeia como membro efectivo do Processo de Bolonha e das suas instâncias coordenadoras.

O EEES configura hoje uma nova ordem educacional nas dimensões em que temos procurado apreendê-la: enquanto governação, ação, agenda e modelo(s) educacionais (ANTUNES, 2006); nestes diversos âmbitos as relações sociais têm vindo a ser alteradas para delinear regimes societais, instituições e sujeitos emergentes. Nesse sentido, o EEES é ainda um programa político em realização, já dotado de instrumentos de ação, ainda que sem uma arquitectura institucional que suporte a sua existência. Somos, assim, testemunhasprotagonistas da invenção e institucionalização de realidades inéditas em educação.

O Processo de Bolonha procura construir uma nova coordenação, escalar e funcional, das actividades envolvidas na educação superior: segundo um novo modelo em desenvolvimento, quer o financiamento, o fornecimento, a regulação ou a propriedade podem ter lugar ou combinar diferentes escalas, supra, sub ou de âmbito nacional, e também ser assumidas por, ou envolver, o Estado, o mercado, a comunidade/terceiro sector ou o agregado doméstico - a governação do ensino superior parece deslocar-se em direcção a um sistema político de múltiplos níveis (PIERSON; LEIBFRIED, 1995) e modelos e arranjos institucionais contrastantes com aqueles até hoje dominantes na Europa.

Do mesmo modo, como sublinhamos, é a acção política supranacional que protagoniza esta construção, com os Estados a transferir deliberada e inopinadamente prerrogativas de decisão do nível das instituições deliberativas nacionais para instâncias adhoc intergovernamentais, como as cinco Conferências Ministeriais - seguidas de outras tantas Declarações ou Comunicados - de 1999, 2001, 2003, 2005 e 2007. Assim, o extenso programa de mudanças no ensino superior no continente europeu ${ }^{3}$ tem vindo a ser decidido a nível de uma plataforma intergovernamental, cuja existência nunca foi expressamente legitimada, avalizada ou escrutinada por qualquer instância emanada dos sistemas políticos democráticos, nacionais ou internacional. Na verdade, publica e aparentemente os Ministros assumem apenas compromissos políticos de realização das mudanças ou diligências acordadas; não se verificam quaisquer normas vinculativas ou sanções jurídicas ou outras; no entanto, às instâncias nacionais, implicitamente é acometida a concretização dos objetivos ou metas apontados. Em Portugal, por exemplo, tudo se passa como se as decisões tomadas nos acordos ministeriais intergovernamentais, não mandatados, nem discutidos previa e

\footnotetext{
${ }^{3}$ Esta reforma envolve a edificação de múltiplos sistemas de âmbito continental: um sistema europeu harmonizado de (três) graus; de transferência de créditos; eventualmente, de garantia de qualidade e de acreditação
} 
publicamente por nenhum órgão do sistema político, fossem vinculativos ainda que vindo a carecer da aprovação a posteriori de instâncias deliberativas nacionais como o Parlamento. Mais incompreensível ainda é que estas constantes apontadas para o Processo de Bolonha, em curso há vários anos, não apenas têm sido tacitamente aceites pelas forças políticas que protagoniza(ra)m o Governo, como continuam pouco mais que ignoradas pelos partidos da oposição à esquerda e à direita, bem como pelas associações de estudantes, pelos sindicatos e instituições do sector. Apenas alguns estudiosos e umas poucas vozes têm procurado interpelar rigorosa, aprofundada e criticamente o Processo, chamando a atenção para as entorses, atropelos e riscos que pode conter (AMARAL, 2002a, 2002b; ROSA, 2003; VICENTE, 2003; ANTUNES 2004a e b, 2005; LIMA, 2006).

As profundas alterações no campo da atuação e decisão (e negociação) políticas em educação, como em outras áreas, os vieses significativos face ao sistema político democrático representativo que é ainda o modelo assumido pelos Estados europeus, os novos arranjos institucionais, forjados na ação e luta políticas quotidianas, como ocorre com o Processo de Bolonha/EEES, têm sido largamente subvalorizados e ignorados, mesmo quando, como neste caso até 2005, excluem ostensiva e liminarmente a representação dos docentes e investigadores europeus.

A ação transnacional exerce-se ainda por via da nova (e débil) institucionalidade estabelecida para o Processo de Bolonha que inclui um conjunto de membros consultivos, constituído por entidades supranacionais com estatuto diverso: a UNESCO, o Conselho da Europa (CE), a Associação Européia de Universidades (EUA), a Associação Européia das Instituições de Ensino Superior (EURASHE), a União de Estudantes Europeus (ESIB), representando as Associações Nacionais de Estudantes na Europa ou, apenas desde 2005, a Internacional da Educação (IE), que federa associações de docentes da Europa e do mundo. Estas entidades procuram influenciar as decisões reunindo com deputados ao Parlamento Europeu e outros responsáveis políticos, organizando seminários ou encontros, produzindo documentos ou estudos. A modelação das políticas e estratégias de reestruturação do ensino superior no quadro de um debate transcontinental protagonizado por influentes organizações internacionais é um tópico de investigação bem estabelecido, ainda que insuficientemente conhecido (CATANI; OLIVEIRA, 2000).

O Processo de Bolonha/EEES tem sido analisado como um programa político globalmente estruturado, cujas conexões com outras estruturas e dinâmicas sociais parece, em alguns casos, não suscitar demasiadas dúvidas enquanto em outras dimensões e vertentes as 
articulações com agendas e pressões globais serão menos visíveis. Desse modo, têm sido sublinhadas: (i) as conexões não-lineares, nem pré-determinadas, ainda que inegáveis, com o programa de liberalização da Organização Mundial do Comércio (OMC) e do Acordo Geral do Comércio de Serviços (AGCS), bem como com a constituição do mercado de serviços na União Europeia (AMARAL 2002a; ANTUNES, 2005a); (ii) a procura de uma correspondência funcional, o que não significa bem sucedida, com a anunciada economia do conhecimento, apoiada em mão-de-obra com escolarização terciária, mas distinta dos estudos superiores prolongados proporcionados pelos sistemas europeus (AMARAL, 2004); (iii) a tentativa de reverter a subida dos custos da expansão dos sistemas públicos de ensino superior, procurando manter ou aumentar as taxas de escolarização e distribuir as despesas com outras entidades, designadamente os próprios estudantes e diminuindo a parte do Estado (AMARAL, 2002b; VICENTE, 2003; ROSA, 2003).

Por outro lado, a mobilidade transnacional e o cosmopolitismo, a individualização das biografias e a educação/aprendizagem ao longo da vida, enquanto necessidade estrutural das nossas sociedades de modernidade tardia, constituem ainda dinâmicas em que ancoram ou a que pretendem responder algumas linhas de acção do programa do Processo de Bolonha/EEES.

A nova ordem das relações sociais em educação está a constituir-se ainda segundo modelos que alcançam uma visibilidade mais nítida em torno de padrões de regulação (DALE, 1997) em fase de institucionalização. A deslocação da intervenção directa do Estado através de normas e sanções, pela criação de patamares intermédios, constituídos pelos sistemas de garantia de qualidade e de acreditação e protagonizados por entidades independentes, tenderia a configurar uma regulação mais próxima do modelo de mercado. Nesse sentido, o Processo de Bolonha e o EEES constituem uma das arenas em que mais vincadamente e de modo específico ocorre a luta e a disputa entre forças e interesses sociais para determinar se, como e em que medida as relações sociais de educação permitem concretizar um direito humano e edificar um espaço político-cultural cosmopolita ou constituir uma mercadoria ou bem privado nos termos de um mercado transnacional.

\section{GOVERNAÇÃO E REGULAÇÃO DO ENSINO SUPERIOR: NOVOS MODELOS E INSTRUMENTOS}

Pela sua importância e conotações múltiplas, procuraremos esboçar o campo teóricosemântico do conceito de regulação, já que a problemática a seguir discutida em grande 
medida aí se inscreve, inspira ou referencia. Assim, apoiando-nos nos teóricos da Escola da Regulação francesa definiremos o modo de regulação como a trama de instituições que favorecem a congruência dos comportamentos individuais e colectivos e medeiam os conflitos sociais chegando a produzir as condições para a estabilização (sempre temporária e dinâmica, ainda que prolongada) de um dado regime de acumulação (BOYER, 1987, p. 54-5; AGLIETTA, 1997, p. 412, 429); constitui, por isso, "um conjunto de mediações que mantêm as distorções produzidas pela acumulação do capital em limites compatíveis com a coesão social no seio das nações" (AGLIETTA, 1997, p. 412). Neste sentido, a regulação pode ser entendida como o conjunto de actividades, tendentes à estabilização e institucionalização, temporárias, dinâmicas, mas prolongadas, orientadas para produzir essa congruência de comportamentos individuais e colectivos, para mediar os conflitos sociais e para limitar as distorções, produzidas pelo processo de acumulação, a níveis compatíveis com a coesão social. Para Roger Dale, regulação designa, neste contexto, as actividades de controlo, isto é, de definição do enquadramento para o fornecimento dos serviços educativos, que o Estado assume através de políticas e sanções legais (DALE, 1997, p. 277). Parecendo consistir, nesta formulação, numa atribuição última daquele, é possível, no entanto, admitir que outras instâncias ou entidades desempenhem igualmente aqui um papel em áreas definidas pelo, e porventura por delegação do, Estado. A regulação implica, assim, a definição de padrões e regras que constituem o quadro em que as instituições operam (DALE, 19974). Roger Dale tem, no entanto, argumentado que o Estado não reteve o controlo da regulação, mas constituiu-se como "regulador de último recurso", isto é, mantém "a autoridade" e "a responsabilidade" pela governação da educação, embora não controle o modo como são coordenadas as atividades que aquela envolve (DALE, 2005, p. 67). Para Barroso, "num sistema social complexo (como o sistema educativo) existe uma pluralidade de fontes, finalidades e modalidades de regulação em função da diversidade dos atores implicados (das suas posições, dos seus interesses e das suas estratégias)". Dessa forma, "a coordenação, o equilíbrio ou transformação do funcionamento do sistema educativo resultam antes da interação dos múltiplos dispositivos reguladores" (BARROSO, 2003, p. 10). Este autor distingue três modalidades de regulação baseadas em alianças distintas entre atores decisivos no campo educativo: uma regulação burocrática, edificada ao longo do processo de desenvolvimento dos sistemas educativos e que corresponderia a uma aliança entre o Estado e os professores; uma regulação baseada no mercado, visível em muitos países, sobretudo

\footnotetext{
${ }^{4}$ Dale apoia-se, para o desenvolvimento desta argumentação em Hood (1995) e Majone (1990).
} 
anglófonos, a partir dos anos oitenta e que envolveria uma aliança do Estado com os pais, sobretudo da classe média; uma regulação baseada na comunidade, ensaiada em processos desenvolvidos ao nível local, por exemplo em Portugal nos últimos anos, e que seria sustentada por alianças entre os professores e famílias (BARROSO, 2003, p. 11-2). Consideraremos, então, a regulação no campo da educação como: (i) o conjunto de mecanismos postos em ação para produzir a congruência dos comportamentos, individuais e coletivos, e mediar os conflitos sociais bem como limitar as distorções que possam ameaçar a coesão social incluindo, em particular, (ii) a definição de padrões e regras que estabelecem o quadro para o funcionamento das instituições.

Segundo Dale, a natureza e o significado da regulação terão sofrido mudanças nos últimos anos: por um lado, a sua forma ter-se-á transformado, passando do que tem sido apreendido como uma forma de regulação determinada por regras, que opera a montante do funcionamento, através dos inputs - isto é, das condições (normas, orientações, recursos, políticas...) fornecidas ao sistema educativo -, para uma forma de regulação determinada por objectivos que actua a posteriori, assente em determinadas realizações (outputs) do sistema (DALE, 1997, p. 279, 2005). Mas, a mudança terá agora alcançado um outro patamar, em que a base da regulação reside nos resultados (outcomes) determinados para o sistema. Assim, os resultados requeridos do funcionamento dos sistemas educativos devem ser traduzidos em desempenhos/produtos/saídas imediatas exibidos pelas escolas e face aos quais estas serão avaliadas. Dale argumenta que a agenda supranacional para a educação e formação se constitui já como parte desta última forma de regulação e que as avaliações do tipo dos estudos PISA representam uma ilustração deste mecanismo de controlo de resultados. ${ }^{5}$

Por outro lado, em convergência com a análise que sinaliza a emergência e importância da forma de actuação como Estado-articulador (SANTOS, 1998; ANTUNES, 2001), Dale enuncia uma mudança do papel do Estado, do controlo da regulação para a autoridade sobre esta; como foi defendido também por Santos (1998), cabe-lhe agora a metaregulação, isto é, a definição dos contextos, condições e parâmetros para a negociação e confronto dos interesses sociais ou, dito de outro modo, deve assumir o estabelecimento das

\footnotetext{
${ }^{5}$ Trata-se do Programme for International Student Assessment (PISA), desenvolvido pela OCDE a partir de 2000 para medir as competências dos jovens de 15 anos; não se pretende avaliar aquisições escolares, mas os desempenhos face a tarefas, definidos aqueles pelos técnicos da OCDE como expressão de competências importantes. As primeiras avaliações PISA, em 2000, envolveram uma amostra de jovens de 15 anos de 32 países (28 Estados-membros da OCDE, bem como a Rússia, Lituânia, Brasil e Liechtenstein) e incidiram maioritariamente sobre o domínio da leitura e compreensão da escrita; o PISA2002 incidiu sobretudo no domínio da matemática e ciências e envolveu mais 13 países (cf. OECD, 2001; Cussó \& D'Amico, 2005).
} 
regras do jogo e da responsabilidade em última instância, face aos fracassos e abusos na regulação (DALE, 2005).

\subsection{ESTRATÉGIAS DE MUDANÇA}

Algumas das mais importantes alterações na governação da educação têm sido perseguidas através de três estratégias: a desregulação, a judicialização (juridification) e a Nova Gestão Pública (DALE, 1997). A agenda supranacional que tem vindo a ser desenvolvida através dos Processos de âmbito europeu, com forte protagonismo ou apoio da União e da Comissão Européias, consiste, em boa parte, em prosseguir aquelas dinâmicas. A desregulação tem em mira a remoção de barreiras e obstáculos à livre circulação de determinado produto ou serviço e à escolha do consumidor. Trata-se de remover as formas de controlo existentes, de natureza burocrática (concursos, ...) ou democrática (instâncias multilaterais, órgãos representativos), percebidas como ameaçadoras para o programa de liberalização. Tipicamente, a desregulação liquefaz as fronteiras geográfico-políticas e territoriais para maximizar o valor de troca e, portanto, potenciar o poder inscrito na capacidade aquisitiva, capital econômico e cultural e/ou no estatuto individual e coletivo.

O programa que se encontra em execução com o chamado Processo de Bolonha inclui uma vertente de desregulação sui generis, que intenta eliminar especificidades e autonomias nacionais substituindo-as por uma férrea regulação de nível supranacional. De fato, as condições, procuradas geralmente através de programas de desregulação (livre circulação, concorrência e escolha de um dado produto), são neste caso sustentadas por meio de um musculadíssimo e duríssimo programa de formatação dos cursos e graus; trata-se, portanto, como em outras áreas, de um processo de dupla face: remoção de barreiras atentatórias do objetivo de liberalização (singularidades, vínculos e recursos político-culturais e institucionais) e imposição de novos parâmetros compatíveis com aquele desígnio. Amaral \& Magalhães chamam a atenção exatamente para esse risco de descaracterização e uniformização, argumentando convincentemente com base em desenvolvimentos com sentidos menos proclamados como a sugestão de definição de currículos ou de programas nucleares europeus (AMARAL; MAGALHÃES, 2004, p. 88).

De acordo com Dale (1997), uma das mudanças mais expressivas tem ocorrido ao nível do padrão de regulação, com os países da Europa a abandonar aquele que constituiu a sua orientação típica de intervenção do Estado, quer diretamente, quer através da legislação, para adotar o modelo mais caracteristicamente americano de entrega de parte substantiva 
dessas funções a entidades supostamente independentes, no sentido de que formalmente não ostentam vínculos, contratuais, por exemplo, com nenhuma das partes reguladas (veja-se em Portugal a (durante largos meses paralisada) entidade reguladora da saúde ou a autoridade que regula a concorrência). Desta forma, o prenunciado estabelecimento, de âmbito europeu e nacional, de agências de avaliação, de garantia de qualidade e de acreditação, nomeadamente nos domínios do ensino e da formação profissionais e do ensino superior, é o passo necessário para que seja possível a transição para este padrão regulatório decalcado do modelo americano de organização de mercados.

A reestruturação da natureza cultural, política e social de determinadas esferas da vida coletiva através da consagração em lei de orientações e constrangimentos que assumem determinados interesses parciais e parcelares como constituintes da própria comunidade, e como tal imperativos na sua própria substância, constitui o processo de judicialização progressiva e extensiva da vida social (DALE, 1997, p. 278; SANTOS, 1998, p. 27-8). Este desenvolvimento subtrai amplas áreas à verificação de dinâmicas de representação, gestão e negociação de interesses e de confronto e conflito políticos; nesse sentido participa do processo mais amplo de limitação da democracia como tentativa para lidar com as exigências e reivindicações crescentes das populações sem perdas de legitimação insustentáveis (a criação do Banco Central Europeu e do Pacto de Estabilidade e Crescimento são exemplos conhecidos de tal estratégia de que o chamado Processo de Bolonha será um simulacro com peculiares características e conseqüências).

Em relação a este último estamos perante um acordo político - de nível ministerial e com a força de uma conferência e uma declaração intergovernamentais, declaração esta que, em Portugal, é apresentada e percebida, pela generalidade dos atores políticos, como um compromisso vinculativo de Estado, com força legal, e, portanto, de natureza imperativa que é traduzido em normativos legais e, finalmente, obtém força jurídica, alcançada no final do processo ainda que evocada desde o início; diríamos tratar-se de um processo sui generis em que, num certo sentido, estamos perante efeitos de judicialização de fato que antecedem e geram um processo de judicialização de direito (em sentido próprio): um compromisso (supostamente com força e legitimidade legal) é evocado para justificar a dispensa dos processos políticos estabelecidos no seio dos sistemas democráticos nacionais, que ocorrem apenas para dar cobertura legal a decisões anteriores assumidas como definitivas.

Esta espécie de judicialização (a posteriori), com conseqüências reais, constitui, como tem sido já freqüentemente alertado, uma manifestação do designado défice 
democrático que marca os processos, instituições e sistema políticos europeus/da União Européia (SANTOS, 1995, p. 286); diversas vozes têm já apontado a tentativa de silenciar e evitar dissensos, substituindo debates e documentos de discussão por eventos e proclamações celebratórios (AMARAL; MAGALHÃES, 2004) solidários desse "modelo bipolar" "exclusivo e excludente" que marca "a nova arquitectura e o novo elenco do campo da educação" no contexto europeu (ANTUNES, 2004a, 2005b) ${ }^{6}$.

A ênfase (tipicamente inspirada nos mandamentos da Nova Gestão Pública) na prestação de $\operatorname{contas}^{7}$ - ao Grupo de Seguimento, no caso do Processo de Bolonha - sugere estarmos perante a forma de regulação determinada por objetivos, sem que, nesta fase, estes cheguem a ser traduzidos por resultados obtidos pelos sistemas educativos. No entanto, a execução das linhas de ação definidas em cada encontro periódico nas Conferências Ministeriais é minuciosamente monitorizada, com pedidos de relatórios nacionais, pedidos de informação às entidades responsáveis e elaboração de múltiplos relatórios, apresentando indicadores de realização, gráficos de consecução, cartões de resultados (scorecards), listas e tabelas de desempenho comparado, em suma, uma impressionante produção de instrumentos, procedimentos e metodologias de controlo, por parte de entidades extranacionais, gritantemente contrastantes com a virtual ausência de acompanhamento, responsabilização, ou mesmo simples informação, perante os atores, grupos ou categorias envolvidos no terreno da ação quotidiana de realização das missões, funções e políticas educativas institucionais e nacionais. ${ }^{8}$

\footnotetext{
${ }^{6}$ A questão de realizar ou não referendos nacionais de ratificação do rebaptizado Tratado Reformador Europeu ou Tratado de Lisboa, cópia conforme segundo diversos analistas do sub-reptício e rechaçado Tratado Constitucional, é uma clara evidência das convicções das elites políticas e órgãos de governo europeus que declaram abertamente recusar um veredicto popular contrário aos seus consensos, ao mesmo tempo que afirmam a necessidade de aproximar os cidadãos da Europa. O acompanhamento deste processo ao longo de 2008 indicará a qualidade ou défice democrático dos sistemas políticos na União.

${ }^{7}$ Para uma discussão alargada das relações entre as reformas da educação dos anos 90 na Europa, a prestação de contas e a avaliação em educação e as propostas da nova gestão pública, consultar Afonso (1998).

${ }^{8}$ Apenas para delinear um quadro aproximado da informação de monitorização produzida para a Conferência Ministerial de Maio de 2005, em Bergen, podem ser listados: (i) relatórios nacionais, elaborados para o Grupo de Seguimento de Bolonha (BFUG, Bologna Follow-Up Group); (ii) From Berlin to Bergen, o Relatório Geral do Grupo de Seguimento de Bolonha (iii) Bologna Process Stocktaking, relatório do Grupo de Trabalho apontado pelo BFUG; (iv) Trends IV: European Universities Implementing Bologna, relatório elaborado sob responsabilidade da Associação das Universidades Europeias (EUA); (v) Focus on the Structure of Higher Education in Europe, documento preparado pela rede Eurydice abrangendo os 40 países signatários do Processo de Bolonha; (vi) The Black Book of the Bologna Process, relatório do ESIB, organismo que representa as associações nacionais de estudantes da Europa (para aceder a estes documentos, consultar a página oficial do Processo de Bolonha, http://bologna-bergen2005no/).
} 
Desse modo, o método de concretização do programa inclui como elemento crucial a determinação dos procedimentos de controlo do seu grau de consecução. Esta lógica resulta da opção pela resolução "de impasses políticos através do recurso a instrumentos técnicos" e pela reorientação das "questões políticas para o domínio mais difuso da governação" em que imperam "indicadores e parâmetros de referência («benchmarks»), agências de regulação, redes de peritos, prestação de contas mútua («mutual accountability»), acordos de partenariado, trocas das melhores práticas" (NÓVOA, 2005, p. 199).

Os efeitos indiretos dos processos de globalização na governação da educação são francamente visíveis quanto a algumas das mais importantes dinâmicas em curso de âmbito supranacional no que respeita ao Processo de Bolonha. Os desenvolvimentos analisados como "a constitucionalização do projeto neo-liberal" e a ampliação das áreas e a intensificação da freqüência com que os estados atuam segundo a forma de estado-em-rede constituem a fonte de onde emanam diversos momentos e vertentes destes processos. Encontramos assim, projetos de alteração da regulação (e, portanto, da governação) da educação quer no que toca à divisão e combinação de escalas em que aquelas se inscrevem, quer no que respeita ao padrão de governação e de regulação: dessa forma, as instâncias supranacionais assumem determinadas atividades (a definição do padrão e da forma de regulação, dos objetivos dos sistemas, dos resultados e das modalidades e procedimentos de controlo) enquanto para os níveis nacional e local será naturalmente preconizado que venham a tomar corpo medidas políticas e processos que respondam àquela agenda. Também quanto ao padrão de regulação e, nomeadamente no que toca ao Processo de Bolonha, o Acordo Geral de Comércio de Serviços parece estar no horizonte, tal como o mercado interno de serviços da União Européia, inspirando a aproximação, através da criação de dispositivos e entidades que protagonizam a regulação (como os sistemas e agências de garantia da qualidade e de acreditação), ao modelo norte-americano de regulação de mercados. Por outro lado, tem vindo a ganhar espaço e impacto a forma de regulação determinada por objetivos, desenvolvimento amplamente visível nos processos de gestão de mudança social e educativa em curso relativamente aos diversos setores dos designados sistemas educativos. 


\subsection{A NOVA ORDEM DA REGULAÇÃO: SENTIDOS, MODELOS E INSTRUMENTOS}

O Processo de Bolonha e o EEES, mercado ou cosmopolitismo?

Tomando agora como referência as dez linhas de ação definidas nas declarações de Bolonha (1999), Praga (2001) e Berlim (2003) ${ }^{9}$, podemos identificar seis categorias referenciáveis a sentidos divergentes para o projeto de edificação do(s) Espaço(s) Europeu(s) de Educação (de Ensino Superior, de Investigação). Não é indiscutível em que consistem estes projetos europeus; parecem, no entanto, apontar para o esbatimento de fronteiras várias entre sistemas, instituições, espaços e percursos. Cremos, no entanto, que essa diluição de fronteiras verifica processos altamente diferenciados e ambivalentes, testemunha fenômenos de sentido contraditório, com origens, intensidades e conseqüências significativamente divergentes. Assim, quer a constituição de um mercado, com base numa regulação mais exigente ou minimalista, quer o aprofundamento da cooperação ou mesmo a edificação de um cosmopolitismo europeu no campo da educação se apresentam como orientações possíveis, embora não igualmente prováveis, dos desenvolvimentos propostos e em curso. Como bem sublinham Stoer e Magalhães, a Europa é uma construção política onde se posicionam diversas visões, projetos ou metáforas e onde o conhecimento como interação cosmopolita ou sob a forma de fluxos e redes disputam terreno, do mesmo modo que "as formas emergentes de regulação encerram importantes potencialidades de agência social e individual" (STOER; MAGALHÃES, 2005, p. 145).

\footnotetext{
${ }^{9}$ Consultar os documentos seguintes: Declaração de Bolonha (1999). Joint Declaration of the European Ministers of Education, Convened in Bologna on the 19th of June 1999, em http://www.europa.eu.int/comm/education/bologna_en.html (consultado em 4 Setembro de 2003); Towards the European Higher Education Area, Comuniqué of the Meeting of Europen Ministers in Charge of Higuer Education in Prague on May 19th 2001, in http://www.europa.eu.int/comm/education/bologna_en.html; "Realising the European Higher Education Area" Comunique of the Conference of Ministers responsible for Higher Education in Berlin on 19 September 2003, in http://www.bologna-berlin2003.de/en/aktuel/index.htm.
} 
Assim, aquelas dez linhas de acção podem ser agrupadas sob as seguintes categorias: mobilidade; convergência; regulação; cooperação/cosmopolitismo; mercado ${ }^{10}$. Como se pode verificar, este rápido esboço de categorização das linhas de ação indicia a ambigüidade potencial de tais orientações, permitindo ainda sublinhar o fato de que, sobretudo a convergência, sendo dispensável, no caso da prevalência do encorajamento da cooperação entre instituições de ensino superior europeu, tendo em vista a construção de um espaço científico-cultural cosmopolita, é um alvo incontornável se, pelo contrário, é a constituição de um mercado concorrencial que domina a agenda ${ }^{11}$. Desta forma, o quadro delineado sugere e reforça, por seu lado, a interpretação de que a criação de condições para a competição entre instituições e espaços econômico-políticos marca a natureza e o ritmo do Processo de Bolonha (AMARAL; MAGALHÃES, 2004; NEAVE, 2004).

Novos instrumentos de regulação: garantia da qualidade, acreditação, reconhecimento

$\mathrm{Na}$ Conferência Ministerial de Bergen foram definidas três grandes áreas de desenvolvimento de políticas em direção aos objetivos acordados no período entre 2005-2007 apresentadas como "características chave da estrutura do EEES" (cf. The European Higher Education Area - Achieving the Goals, p. 6). Assim, a intensa atividade demonstrada na

10

\begin{tabular}{|l|l|l|l|l|l|}
\hline $\begin{array}{l}\text { Objectivos } \\
\text { (declarados ou } \\
\text { possíveis) }\end{array}$ & mobilidade & convergência & regulação & mercado & $\begin{array}{l}\text { cooperação/ } \\
\text { cosmopolitismo }\end{array}$ \\
\hline $\begin{array}{l}\text { Linhas de } \\
\text { acção }\end{array}$ & 1 & 1 & 1 & 1 & 1 \\
& 2 & 2 & 3 & 2 & 3 \\
& 4 & 3 & 5 & 3 & 4 \\
& 10 & 10 & 10 & 7 & 6 \\
& & & & 9 & 10 \\
\hline
\end{tabular}

Recordamos que as linhas de acção definidas para o Processo de Bolonha são as seguintes: 1- Adopção de um sistema de graus facilmente legível e comparável; 2- Adopção de um sistema essencialmente baseado em dois ciclos; 3- Estabelecimento de um sistema de créditos; 4- Promoção de mobilidade; 5- Promoção da cooperação Europeia na garantia de qualidade; 6Promoção da dimensão Europeia no ensino superior; 7- Aprendizagem ao longo da vida; 8- Instituições do Ensino Superior e Estudantes; 9- Promover a atractividade do Espaço Europeu de Ensino Superior; 10- Estudos de doutoramento e a sinergia entre o Espaço Europeu de Ensino Superior e o Espaço Europeu de Investigação. De notar que em documentos oficiais laconicamente se afirma o entendimento de que a dimensão social do ensino superior (linha de acção proposta e requerida repetidamente pela organização representativa dos estudantes, como membro consultivo neste processo, a ESIB - the National Unions of Students in Europe), deve ser entendida como uma linha de acção envolvente (overarching) ou transversal, sem qualquer explicitação adicional da tradução concreta de tal entendimento (cf. Work programme $2003-2005$ for the Bologna Follow-Up Group).

\footnotetext{
11 Uma tipologia de "racionalidades políticas e abordagens à educação transnacional", construída pela OCDE, apresenta quatro modalidades: (i) compreensão mútua (com uma longa história, de que os programas Socrates-Erasmus promovidos pela União Europeia são, entre outros, apresentados como exemplos ilustrativos); (ii) migração qualificada; (iii) geração de rendimento; (iv) construção de capacidade (apresentadas como abordagens com uma forte orientação económica e emergentes nos anos 1990's) (OCDE, 2004, p. 4-5).
} 
edificação de um novo quadro de regulação em que as instituições operam (DALE, 1997) envolve: (a) um modelo convergente assente na definição de uma unidade de medida (o crédito europeu), que vigore no domínio da formação profissional e do ensino superior, e que permita definir padrões similares ou equivalentes para um número amplo de cursos, diplomas e instituições; (b) a definição de um único sistema de graus em que podem ter lugar variações mínimas ainda contrariadas pela sugestão de uma versão preferencial, anglo-saxónica, na modalidade $3+2$ anos ou 180+120 créditos europeus para os dois primeiros ciclos; (c) o esforço para fundar sistemas de avaliação, de garantia de qualidade e de acreditação, com base em entidades e procedimentos que se pretende articular, quer ao nível nacional, quer transnacional ${ }^{12}$ (ANTUNES, 2005b).

A centralidade assumida pelas operações de racionalização, codificação e mensuração das aprendizagens (a omnipresença dos créditos europeus, como unidade de medida e dos resultados de aprendizagem como codificações e racionalizações destas) acentua a suspeita de que o sentido imprimido a este processo resultará primordialmente das trocas, comerciais e não essencialmente culturais, assim potenciadas. A qualidade, transparência e comparabilidade erigidas em altos desígnios do Espaço Europeu de Ensino Superior constituem termos destituídos de densidade cultural, incapazes de descrever, expressar ou mobilizar intercâmbios e fertilizações culturais mutuamente desejados e enriquecedores consonantes com um projeto comprometido com a cooperação e o cosmopolitismo. A instituição de uma unidade de medida com a pretensão de vir a tornar-se a tradução universal de processos educativos e de aprendizagens ameaça deslizar sem transição do esboço de uma caricatura para um perigoso e poderoso meio de esvaziamento e empobrecimento da complexidade das dinâmicas educativas e das relações interculturais. Nesse sentido, a perspectiva de uma cultura (global) de casino, assente nas trocas comerciais de aprendizagens que, como argumenta Bernstein, circulam sem chegar a afetar os sujeitos (BERNSTEIN, 1998), desenha-se como horizonte cada vez mais provável em resultado de desenvolvimentos e cursos de ação hoje efetivamente presentes.

Por seu turno, os sistemas de garantia de qualidade representam, na óptica de alguns especialistas, um novo estrato avaliativo e normativo, entre as instituições e a administração, cujo "alvo estratégico" é "injetar o princípio de competição entre as universidades

\footnotetext{
12 Andreas Fejes argumenta que o Processo de Bolonha constitui uma técnica de padronização (de que o sistema de transferência de créditos europeu (ECTS) e o suplemento ao diploma fazem parte) associada à técnica de determinação de objectivos, constituindo ambas modos de governar, isto é de constituir e gerir sujeitos (universidades, nações, estados, cidadãos) (Fejes, 2005: 14 e ss.).
} 
individuais", constituindo expressões desse "curioso paradoxo Europeu" que consistiu em ser o Estado "a injetar o princípio de mercado na educação superior” (NEAVE, 2004, p. 8-9; AFONSO, 1998, p. 76).

Ainda de acordo com outros estudiosos, o modelo de acreditação adotado no contexto do sistema de ensino superior dos Estados Unidos da América, hoje em crise e sujeito a amplas críticas, parece ser o objeto de emulação selecionado para incluir o denominado Processo de Bolonha; aquele modelo de acreditação apresenta-se congruente com um sistema de ensino superior em que "o mercado desempenha o papel principal enquanto o governo federal está ausente da regulação do sistema" e tem sido objeto de tentativas persistentes no sentido de aparecer como consensual nos documentos oficiais, apesar de o acolhimento de tais propostas, pelos responsáveis e representantes de instituições e atores, ter sido marcado pela contestação, controvérsia e discórdia. (AMARAL; MAGALHÃES, 2004, p. 89-94). Assim, de acordo com Amaral, a conjugação da regulação através de uma "definição dos "outcomes" disciplina a disciplina" com "sistemas de acreditação Europeus, irá criar uma burocracia intolerável e asfixiante" (AMARAL, 2004, p.6).

A trilogia de instrumentos (garantia de qualidade - padrões e orientações -, reconhecimento e acreditação), que encontramos na forja no âmbito daquele Processo, é associada, no programa da Conferência Ministerial de Bergen, à criação de uma nova realidade que é a prestação de serviços de educação através de fronteiras; trata-se de preparar a Europa para esse universo em expansão em que a educação se constitui como uma componente do setor dos serviços cuja governação está em mutação. Naquele documento, a alteração do padrão e da escala de governação são apresentados como dados (um padrão de governação em que o Estado não é um protagonista central, em que o mercado se torna uma importante, senão a principal, forma de coordenação social, em que o fornecimento e a regulação abrangem o nível supranacional); o que está em debate são a forma e o padrão da regulação, nas acepções atrás discutidas. As alternativas surgem circunscritas entre, por um lado, a construção de um edifício consolidado de regulação com base naqueles três pilares (garantia de qualidade, acreditação, reconhecimento) e, por outro lado, uma regulação minimalista determinada pelos requisitos de funcionamento do mercado e assente nas interações e acordos daí resultantes. Assim, sustenta-se que a criação de uma "base comum de qualidade" no contexto europeu é "um pré-requisito para o EEES", que a garantia de qualidade é uma "responsabilidade das instituições individuais", o reconhecimento diz respeito aos "indivíduos e à sua necessidade de obter qualificações portáteis" e que a 
acreditação institui "um conjunto comum de normas". A afirmação da necessidade de um consenso sobre a qualidade («the need for a quality consensus») é conjugada com a evocação de "um sistema global de reconhecimento" e os desafios e riscos associados a: (i) a gestão e proteção das políticas educativas nacionais; (ii) a garantia sustentada da qualidade em educação face a "fornecedores comerciais relutantes em aceitar uma responsabilidade pelo ambiente educativo em que habitam" e (iii) o comércio globalizado de serviços de educação superior que, "constitui já um segmento significativo do comércio mundial de serviços", pelo que "no contexto do AGCS muitos estão preocupados com o fato de os aspectos da qualidade da educação virem a ser ignorados e marginalizados”.

Nesse sentido, encontramos opções despolitizadas e não discutidas (a educação constitui um serviço cuja natureza permite a sua integração no conjunto de serviços em franca liberalização; o mercado global de educação continuará em expansão; a regulação, neste contexto, deverá assentar nos pilares da garantia da qualidade, reconhecimento e acreditação) e debates assumidos e escolhas fundamentadas: a regulação supranacional da educação politicamente sustentada, assumida e legitimada é claramente adotada como a alternativa a formas de regulação determinadas pelo funcionamento, pelos interesses e forças do mercado, incapazes de "salvaguardar os especiais aspectos de qualidade da educação - especificamente os interesses dos países mais fracos que são as vítimas potenciais de educação transnacional de baixa qualidade e/ou lucrativa" (Conference Programme, 2005, p. 9, 10).

Como refere um autor,

pode defender-se que as convenções da UNESCO podiam constituir um quadro legal alternativo ao AGCS na educação superior. As convenções são instrumentos legalmente vinculativos que foram ratificados por mais de 100 estados membros abrangendo cada região do mundo. (...) A diferença fundamental entre o AGCS e a UNESCO reside no seu propósito, o primeiro promove a liberalização do comércio da educação superior para propósitos de lucro; as Convenções da UNESCO são celebradas com a intenção de desenvolver a internacionalização da educação superior (MATHISEN, 2005, p. 16, 17).

A combinação adotada para este novo quadro regulatório inclui a forma de regulação determinada por regras (a harmonização em torno do sistema de créditos e do sistema de graus), que opera a priori, bem como a forma de regulação determinada por objectivos e resultados («outcomes»), com controlo a posteriori, (o estrato avaliativo (NEAVE, 2004), os sistemas de garantia da qualidade). As eventuais, e ao que tudo indica largamente prováveis, adopção e generalização de formas de acreditação de âmbito europeu (AMARAL; MAGALHÃES, 2004), ou mesmo que nacional, ampliarão o poder normativo daquelas 
instâncias intermédias em relação às opções de gestão e funcionamento das instituições, sendo susceptíveis de aprofundar o impacto das lógicas mercantis e concorrenciais no setor e de reduzir à sua mínima expressão os valores, as lógicas e poderes associados ao trabalho acadêmico.

As dinâmicas em curso na Europa estão longe de constituir singularidades; noutras latitudes, também a indução da concorrência, quase sempre associada a sub-financiamento das instituições públicas e à segmentação ou mesmo desqualificação do setor, em termos de produção do conhecimento, têm sido assinaladas como ameaças, derivas ou imposições de fato. Para alguns autores, "a identidade da instituição universitária" foi colocada sob pressão, visível no "processo de substituição da produção de conhecimento pela administração de dados e informações" à imagem de "empresas prestadoras de serviços" (SILVA JÚNIOR; SGUISSARDI, 2000, p. 105-106). A “incorporação, reconfiguração e difusão local" de conhecimento produzido em outros centros mundiais, enquanto docentes e investigadores diligenciam tornar-se performativos e competitivos gestores de investigação, ensino e serviços, são apresentados como missões e perfis propostos por poderosas organizações internacionais, como o Banco Mundial ou, em certos aspectos, a UNESCO para o Brasil, mostrando as especificidades mas também o pano de fundo comum a transformações iniciadas aparentemente com ambição planetária (SHIROMA; MORAES; EVANGELISTA; 2003 p. 136-46). Outros investigadores apontaram muito claramente o desenvolvimento de um debate internacional sobre "a reestruturação da educação superior", em que avultavam: (i) o seu âmbito pluricontinental, com destaque para os ritmos, processos e mesmo conteúdos diferenciados, por exemplo entre a América Latina e a Europa; (ii) o protagonismo das organizações internacionais e (iii) as orientações comuns, que autorizariam a sugestão de modelação de políticas e estratégias padronizadas de reformas em torno da diversificação e diferenciação das instituições e das fontes de financiamento (CATANI; OLIVEIRA, 2000).

Argumentamos que o Processo de Bolonha impulsiona a edificação de um novo quadro regulatório, no setor do ensino superior; sugerimos ainda que a constituição do mercado interno europeu, em foco com a polêmica directiva Bolkestein, e o Acordo Geral de Comércio de Serviços constituem horizontes orientadores das opções em questão. A convergência em torno de um sistema de graus, a constituição de orientações e padrões comuns para a edificação de sistemas de garantia da qualidade, e o estabelecimento de normas comuns de reconhecimento de graus sugerem que estamos perante a criação de condições, quer para a remoção de controlos e características (de natureza democrática e burocrática) 
impeditivas da livre circulação, concorrência e escolha entre cursos e instituições (desregulação), quer para o estabelecimento de regras e parâmetros em que as instituições operam (re-regulação) compatíveis com a constituição de um mercado eventualmente dotado de uma regulação exigente. A mudança de papel do Estado está em consumação no contexto do neófito Espaço Europeu de Ensino Superior. Como antes se salientava, neste quadro, às autoridades políticas públicas, Estados ou instâncias inter e supraestatais, parece caber a metaregulação, isto é, o estabelecimento das regras do jogo e da responsabilidade em última instância, face aos fracassos e abusos na regulação (SANTOS, 1998; DALE, 2005).

\section{BOLONHA IN SITU: VOZES E ACTORES NA ESPUMA DOS DIAS}

Em Portugal, o processo de reestruturação do sistema de graus tem vindo a decorrer desde 2004, numa primeira fase de modo irregular e com interrupções, com um envolvimento minimalista das instituições, dos seus órgãos e atores, sob pressão explícita da tutela quanto à urgência das operações a levar a cabo e ecos públicos esparsos de um processo político baseado no cumprimento dos rituais de informação e consulta obrigatórios ${ }^{13}$; a reforma que assim se aspira a concretizar terá os sucessos que for possível produzir com o desconhecimento, a incompreensão, a distanciação e a adesão deliberadamente fabricados ao longo dos poucos anos que leva de gestação. Posteriormente, o desenvolvimento daquele núcleo das medidas acordadas em Bergen foi publicamente lançado pelo Ministro da Ciência, Tecnologia e Ensino Superior, Mariano Gago, no final de 2005 com o anúncio de: (i) "uma avaliação global do sistema de ensino superior e das respectivas políticas" da responsabilidade da OCDE (Organização para a Cooperação e Desenvolvimento Econômico); (ii) "uma avaliação dos atuais processos e práticas de garantia da qualidade, de acreditação e de avaliação do ensino superior”, sob a responsabilidade da Rede Européia para a Garantia da Qualidade no Ensino Superior (ENQA), esta última avaliação devendo produzir "recomendações que garantirão a instituição de um sistema nacional de acreditação e de práticas que vão ao encontro dos padrões e das diretrizes para a garantia da qualidade na área

\footnotetext{
${ }^{13}$ Consultar, por exemplo, umjornal, edição de 2 de Julho de 2004, p. 7: “O reitor [da Universidade do Minho, Guimarães Rodrigues] garante que o MCES nomeou o grupo de trabalho das diferentes áreas de conhecimento à margem das reitorias, que não foram informadas sobre esse assunto". Também no Jornal Público, edição de 9 de Novembro de 2005, p. 28, se noticia que "Estudantes da Beira Interior questionam aplicação de Bolonha" contestando a aplicação, por alguns professores, de um regulamento de avaliação "ainda não aprovado em Senado, que tem por base a declaração de Bolonha", enquanto na edição de 24 de Janeiro de 2006, p. 22, se escreve que: "No passado dia 11, o ministro Mariano Gago chamou os principais parceiros para entregar três anteprojectos de decreto-lei, os documentos necessários para regulamentar o processo de Bolonha. O governante deu menos de duas semanas aos parceiros para discutirem e enviarem os pareceres".
} 
européia do ensino superior”; (iii) "um programa voluntário de avaliação institucional de âmbito internacional dos estabelecimentos portugueses de ensino superior universitários e politécnicos, público e privado, e suas unidades orgânicas", a conduzir pela Associação Européia das Universidades (AEU) com a colaboração da Associação Européia de Instituições do Ensino Superior (EURASHE ${ }^{14}$ ). A leitura do normativo legal que consagra estas medidas testemunha vivamente as preocupações, pressupostos e orientações que norteiam este conjunto de opções: trata-se de preparar o país para "os desafios inerentes à garantia de qualidade, capacidade de resposta e competitividade internacional no âmbito do ensino superior", entendimento em diversos passos confirmado como ilustra a discussão de 'estratégias' e 'cenários' respeitantes à garantia da qualidade face ao "notável crescimento nos anos recentes nos domínios da educação transnacional e do que é denominado como novas modalidades de ensino: programas de educação a distância, pólos universitários, franchises, de entre outros" (Despacho $n^{\circ}$ 484/2006 (2 ${ }^{\text {a }}$ série): 333, 332, 336). Porque, no entanto, o futuro se conjuga no plural e comporta múltiplos possíveis, ou mesmo diversos sentidos prováveis, faz-nos falta a informação e o debate públicos - nacionais, parlamentares, institucionais ...- acerca dos horizontes, das alternativas, dos cenários, das suas implicações, do bem fundado ou bem orientado das preocupações e das opções do Governo Português; a parca informação cifrada que fundamenta e legitima a decisão vertida em normativo legal esclarece tão só o caráter da prática política em presença.

Ainda no início de 2006, as instituições foram confrontadas com a possibilidade de concluir de imediato determinadas fases do processo de adequação do ensino superior ao modelo de Bolonha. À aprovação de legislação de alteração da Lei de Bases do Sistema de Ensino na Assembléia da República (em meados de 2005), seguiu-se, então, um inédito processo acelerado de regulamentação e implementação que se saldou pela entrega, até 31 de Março, de cerca de seiscentas propostas de reestruturação de cursos à Direcção-Geral do Ensino Superior para registo de adequação/autorização de funcionamento, com base num Decreto-lei de 24 de Março e orientações técnicas publicadas em data posterior. Procurando apreender alguns ecos desse período na Comunicação Social, impressiona a paradoxal sensação de vertigem e naturalização que emana dos relatos produzidos. Encontramos, face ao Processo, apreciações que percorrem toda a paleta de tonalidades, da adesão eufóricoexpectante ao quase lamento disfórico-resignado, reações que, contudo, tendem a fixar-se nos

\footnotetext{
${ }^{14}$ ENQA, e EURASHE correspondem às siglas da designação destas instituições em língua inglesa.
} 
contornos mais imediatos da reformulação do sistema de graus ou da evocada reorientação pedagógica, por alguns hiperbolicamente designada como paradigma de Bolonha ${ }^{15}$.

$\mathrm{Na}$ verdade, as referências saídas a público centram-se em torno de alguns poucos vectores do Processo: (i) as suas múltiplas agendas, daquela mais explícita, da mobilidade, empregabilidade, competitividade, àquela outra, oculta, mas omnipresente, do financiamento; (ii) o processo político desenvolvido em Portugal; (iii) a perversão dos objetivos ou alcance daquela reforma; (iv) as antevistas conseqüencias (positivas ou negativas) para os estudantes.

Os responsáveis pelas instituições de ensino superior freqüentemente evocam aquela dupla agenda, sublinhando sobretudo a primeira faceta mencionada, ainda que questionando também os efeitos penalizantes da temida redução de recursos. Face à vertigem que percorreu todo o processo de adequação a Bolonha no início de 2006, alguns contestam o estilo de atuação do ministério da tutela: "'Esta forma de trabalhar não é consentânea com o normal funcionamento de um Estado de Direito’ acusa Luciano de Almeida, presidente do Conselho Coordenador dos Institutos Superiores Politécnicos (CCISP)" 16; também o relato da alienação dos estudantes e da sociedade em geral sobressai nos títulos e comentários publicados. Ecoa nestes testemunhos revisitados a reiterada ocorrência de tais desenvolvimentos, que reproduzem e ampliam no espaço nacional e institucional a insidiosa corrosão continuada da substância da democracia, designadamente no terreno da formação e desenvolvimento das políticas.

Um outro registo tende a sublinhar laconicamente uma leitura de que as condições oferecidas em Portugal para a concretização daquele Processo arriscam-se a convertê-lo numa oportunidade perdida: porque se privilegiou a produção de resultados para mostrar externa e internamente quanto à reformulação dos cursos,

Se ao acto formal da aprovação dos diplomas se acrescentar a exacerbação, transmitida pelo MCTES, de uma urgência inusitada na adequação ao novo quadro legal, facilmente se percebe a deriva do processo face aos seus principais objectivos. Aceitando esta deriva, nada falta fazer. Tudo está feito (PEIXOTO, 2006, p. 11).

\footnotetext{
${ }^{15}$ Alguns dos termos e expressões que evocamos em itálico (adequação ao modelo de Bolonha, paradigma, formações ou cursos de Bolonha) repetem referências usadas em normativos legais e/ou saídas na imprensa, quer citando protagonistas envolvidos, quer da autoria de jornalistas. A apropriação que deles fazemos pretende sublinhar o que aparenta constituir o entendimento oficial e mais difundido dos desenvolvimentos em questão (cf. decreto-lei no 74/2006 de 24 de Março).

${ }^{16}$ A citação integra-se no seguinte (con)texto: "No dia 13, o Ministério da Ciência, Tecnologia e Ensino Superior (MCTES) enviou, com carácter de urgência, um documento com os projectos de normas de organização dos dossiers referentes aos processos de registo de alteração dos cursos e de novas formações. Dois dias depois a tutela esperava as respostas das escolas. Um prazo difícil de cumprir quando estas têm de reunir diversos órgãos para analisar os projectos. Passadas duas semanas, as normas ainda não foram publicadas em Diário da República, o que significa que as escolas elaboraram processos sem saber se a lei será igual ao projecto" (cf. Jornal Público, edição de 31 de Março de 2006, p. 26).
} 
ou porque a mesma tutela parece pouco inclinada a fornecer os apoios e recursos necessários para que as instituições assumam esta reforma (FenProf, 2006, p. 4-5). Aflora neste olhar a idéia de que um duro preço será pago no futuro próximo por tais opções.

Por último, os jornais registam ainda apreensão e pessimismo, da parte de estudantes mantidos no desconhecimento, total ou parcial, e que manifestam sobretudo preocupação e insegurança face ao valor das formações e dos diplomas de Bolonha: "Vai cada vez sair mais gente e vai ser mais complicado arranjar emprego" (Jornal Acadêmico, no 20, p. 3); "Menos tempo de estudo, menos preparação, menos possibilidades de emprego" (Jornal Público, edição de 24 de Março de 2006, p. 22).

Cerca de um ano depois, era possível encontrar apreciações que oscilavam entre a constatação de "fortes angústias" nos alunos, quanto às mensalidades a pagar nos mestrados (os chamados $2^{\circ}$ S ciclos de Bolonha) e ao reconhecimento pelas ordens profissionais dos cursos reduzidos para três anos $\left(1^{\circ} \mathrm{s}\right.$ ciclos de Bolonha), e de receios e apreensões nos docentes em torno das novas metodologias, das leituras do que é o trabalho individual dos alunos e dos 'cortes orçamentais que estão a empurrar as escolas a reduzir o pessoal'. Referese que 'o ano de arranque de Bolonha coincidiu com o desinvestimento no ensino superior' ${ }^{17}$; outros ainda dizem-se preocupados com a qualidade da formação que 'vai levar tempo a analisar e a corrigir' ${ }^{18}$.

Após a entrega dos relatórios da OCDE e da ENQA ao Ministro da tutela, está em curso em ritmo acelerado a alteração dos principais diplomas que regulam domínios fundamentais como o Regime Jurídico das Instituições do Ensino Superior, a Agência Nacional de Avaliação e Acreditação do Ensino Superior e o Estatuto da Carreira Docente. Nesta data (Outubro de 2007) entrou já em vigor o primeiro diploma, após um processo que alguém considerou de 'fúria legislativa', com prazos de discussão e num momento (final do ano letivo e legislativo, entre Maio e Julho) largamente contestados pelas diversas forças

\footnotetext{
${ }^{17}$ Em relação a esta questão, o consenso é invulgar na sociedade portuguesa, mercê provavelmente da força dos factos. Júlio Pedrosa - actual presidente do Conselho Nacional de Educação, antigo reitor da universidade de Aveiro e ex- Ministro da Educação do XIII Governo Constitucional, com António Guterres como primeiro-ministro e suportado pelo Partido Socialista -, questionado sobre se "Há subfinanciamento ou há universidades mal geridas?", afirmava por estes dias em entrevista a um jornal: "A resposta é simples: basta compararmos o financiamento por aluno nas universidades portuguesas com a média europeia. É metade. Não podemos usar padrões europeus em relação aos resultados e usar outros padrões para o financiamento" (FERNANDES; ABECASSIS, 2007, p.13).

${ }^{18}$ Trata-se de apreciações de, respectivamente, Luciano de Almeida, João Cunha Serra e Paulo Peixoto (da Federação Nacional de Professores um e do Sindicato Nacional do Ensino Superior, o outro), Seabra Santos (presidente do Conselho de Reitores das Universidades Portuguesas, CRUP) e Sebastião Feyo de Andrade (Vice-Presidente da Ordem dos Engenheiros e delegado nacional do Processo de Bolonha, nomeado pelo Ministro da tutela) inseridas numa reportagem do Jornal Público, edição de 24 de Março de 2007.
} 
políticas e actores do universo académico, desde os estudantes aos sindicatos, ao CRUP, CCISP e Conselho Nacional de Educação.

A breve aproximação à espuma dos dias em que vem tendo lugar a adequação $a$ Bolonha dos cursos do ensino superior pode neste momento suscitar apenas interrogações: Porque se mobilizaram tantas instituições no desejo de estar na primeira linha dos cursos de Bolonha, em condições de tal precariedade e num esforço tão insustentado como se pôde vislumbrar? Com que conseqüências, presentes e futuras? Até quando permaneceremos debatendo Bolonha neste contínuum redondo e opaco da euforia à disforia, da adesão expectante à crítica desencantada, sem que (nos) interpelemos quem decide acerca dos fundamentos e sentidos das suas decisões ${ }^{19}$ ?

\section{UMA NOVA ORDEM NA GOVERNAÇÃO E REGULAÇÃO PARA O ESPAÇO EUROPEU DE ENSINO SUPERIOR}

Argumentamos que o horizonte do Espaço Europeu de Ensino Superior, de que o Processo de Bolonha se vem constituindo um método de ação política, corporiza uma nova ordem educacional em diversas dimensões: (i) uma governação pluri-escalar; (ii) múltiplas modalidades e protagonismos de ação transnacional; (iii) desenvolvimentos e agendas para a educação estruturados por pressões e estratégias político-económicos globais e (iv) disputas entre tendências e modelos de ambição mundial constituem alguns dos processos que conjuntamente desenham aquela realidade educativa emergente de contornos continentais.

Neste terreno se desafiam projetos, se confrontam forças e protagonistas mobilizados para a construção da educação como direito humano ou como mercadoria. A constitucionalização do projeto neo-liberal parece, de momento, a dinâmica largamente prevalecente, ainda que não exclusiva, em contraste com as também atuantes procuras de cooperação e cosmopolitismo, por um lado, e os processos de individualização das trajectórias biográficas, por outro.

Neste contexto, está em construção na Europa um novo quadro regulatório para o setor do ensino superior, envolvendo a trilogia garantia de qualidade, reconhecimento e acreditação, que pode viabilizar a constituição de um mercado eventualmente dotado de uma

\footnotetext{
${ }^{19}$ Um jornal académico reportou uma manifestação de estudantes da Universidade de Coimbra frente à Assembleia da República, a 23 de Março de 2006; segundo a notícia, "O alvo das críticas foi sempre o Governo, por não dar explicações conclusivas sobre as repercussões que a reforma pode produzir na vida académica - «Ninguém nos responde, Portugal está à deriva», insurge-se o presidente associativo. (...) Os lençóis traziam escritas mensagens como «Bolonha não, sim à educação» e «Contra a privatização e elitização do ensino" (cf. Jornal Mundo Académico, edição de 27 de Março de 2006, p. $3)$.
} 
regulação exigente, com as autoridades públicas inter e supraestatais assegurando a metaregulação. Também em Portugal, e declaradamente desde há cerca de dois anos, foi desencadeada uma reforma do ensino superior que está prestes a registar a adequação da totalidade dos cursos de ensino superior ao modelo de Bolonha $\left(1^{\circ}\right.$, e em alguns casos, $2^{\circ}$ ciclos); encontram-se ainda em curso, também a um ritmo alienante, outras alterações de fundo no que toca, por exemplo, à autonomia e governo das instituições.

\section{REFERÊNCIAS}

AFONSO, Almerindo J. Políticas educativas e avaliação educacional. Braga: Universidade do Minho, 1998.

AGLIETTA, M. Régulation et crises du capitalisme. Paris: Éditions Odile Jacob, 1997.

AMARAL, A. À conversa com o Prof Dr. Alberto Amaral. Bolonha: o que está em jogo? (entrevista), Ensino Superior, n. 45, Suplemento ao Jornal da Fenprof ${ }^{\circ}{ }^{\circ} 175$, Janeiro de 2002(a), p. 8-12.

. O viagra dos ministros fracos. DNE Ensino, edição do Diário de Notícias de 5 de Julho de 2002(b), p. 92-93.

. Conferência apresentada na Faculdade de Economia da Universidade do Porto em 22

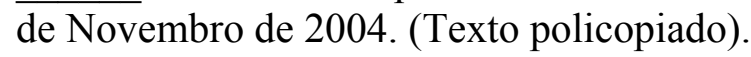

n. 48, p. $79-100$.

.; MAGAlHÃES, A. Epidemiology and the Bolonha saga. Higher Education, 2004,

ANTUNES, F. Os locais das escolas profissionais: novos papéis para o Estado e a europeização das políticas educativas. In: STOER, S. R.; CORTESÃO, L.; CORREIA, J. A. (Org.). Transnacionalização da educação. Da crise da educação à "educação" da crise. Porto: Afrontamento, 2001, pp. 163-208.

. A europeização das políticas educativas: a nova arquitetura e o novo elenco no campo da educação. A Página da Educação, n. 130, p. 7, jan. 2004a.

. A europeização das políticas educativas II: políticas intergovernamentais e realidades nacionais. A Página da Educação, n. 133, p. 34, 2004 b.

. Globalização e europeização das políticas educativas: percursos, processos e metamorfoses. Sociologia. Problemas e Práticas, n.47, p. 125-143. 2005a,

. Regulação supranacional e governação da educação: dimensões européias.

Administração Educacional, ${ }^{\circ}$ 5, pp. 7-20, 2005 b.

BARROSO, J. Les mutations de «l'État éducateur»: de la raison visible de l'État à la 'main invisible' du marche. Conferência apresentada ao Séminaire Printemps.

(C) ETD - Educação Temática Digital , Campinas, v.9, n. esp., p.1-28, dez. 2007 - ISSN: 1676-2592. 
Porto/Faculdade de Psicologia e Ciências da Educação, 3 e 4 de Abril de 2003 (texto policopiado).

BOYER, R. La théorie de la régulation: une analyse critique. Paris: La Découverte, 1987.

CATANI, A. M.; OLIVEIRA, J. F. A reestruturação da educação superior no debate internacional: a padronização das políticas de diversificação e diferenciação. Revista Portuguesa de Educação, v.13, n. 2, p. 29-52, 2000.

CABRAL, M. S. Vigília de protesto contra o Processo de Bolonha. «Vale a pena lutar!». Jornal Mundo Académico, edição de 27 de Março de 2006, p. 3.

DALE, R. The State and the governance of education: an analysis of the restructuring of the State-education relationship. In: HALSEY, A. H. et al. (Org.). Education - culture, economy and society. Nova Iorque: Oxford University Press, 1997, p. 273-282.

. A globalização e a reavaliação da governação educacional. Um caso de ectopia sociológica. In: TEODORO, A.; TORRES, C. A. (Org.). Educação crítica e utopia. perspectivas para o século XXI. Porto: Afrontamento, 2005, p. 53-69.

FENPROF. Posição da FenProf a propósito do anteprojecto de decreto-lei dos graus acadêmicos e diplomas do ensino superior. Sup/Jornal da FenProf, n. 56, suplemento ao Jornal da FenProf nº 207, edição de Fevereiro de 2006, p. 4-5.

FERNANDES, J. M.; ABECASSIS, R. Os programas escolares deveriam centrar-se nos grandes objetivos e não nos detalhes. Jornal Público, edição de 28 de Outubro de 2007, p. 12-13.

FIELD, J. Lifelong learning and the new educational order. Stoke on Trent: Trentham Books, 2000.

INVÊNCIO, S. Estudantes da Beira Interior questionam aplicação de Bolonha. Jornal Público, edição de 9 de Novembro de 2005, p. 28.

LAVAL, C.; WEBER, L. Le nouvel rrdre éducatif mondial. OMC, Banque Mondial, OCDE, Commission Européenne. Paris: Nouveaux Regards/Syllepse, 2002.

LIMA, T. UM prepara-se para o Processo de Bolonha. Críticas ao Ministério. Jornal umjornal, edição de 2 de Julho de 2004, p. 7.

LIMA, L. C. Bolonha à portuguesa? A Página da Educação, n. 160, p. 9. edição de Outubro de 2006.

MAJONE, G. Deregulation or regulation? Regulatory reform in Europe and the United States. Londres: Pinter, 1990.

MALAINHO, R.; OSÓRIO, T. V. Bolonha: o reino das dúvidas e da desinformação. Jornal Académico, n. 20, edição de 8 de Março de 2006, p. 3. 
NÓVOA, A. Les états de la politique dans l'espace européen de l'éducation. In: LAWN, M.; NOVOA, A. (Coord.). L'Europe réinventée. Regards critiques sur l'Espace Européen de l'Éducation. Paris: L'Harmattan, 2005, p. 197-224.

OECD. Knowledge and skills for life: First results from PISA 2000. Paris: OECD, 2001.

PEIXOTO, P. Bolonha: o que falta fazer?. Jornal Público, edição de 12 de Março de 2006, p.11.

PIERSON, P.; LEIBFRIED, S. Multitiered institutions and the making of social policy. In: LEIBFRIED, S.; PIERSON, P. (Org.). European Social Policy. Between Fragmentation and Integration. Washington D. C.: The Brookings Institution, 1995, p. 1-40.

ROSA, R. N.O ensino superior e o processo de Bolonha. A Página da Educação, n. 120, p. $13,2003$.

SANTOS, B. S. Toward a new common sense: law, science and politics in the paradigmatic transition. Londres: Routledge, 1995.

. Reinventar a democracia. Lisboa: Fundação Mário Soares/ Gradiva, 1998.

SILVA JÚNIOR, J. R.; SGUISSARDI, V. Reforma da educação superior no Brasil: renúncia do Estado e privatização do público. Revista Portuguesa de Educação, v.13, n.2, p. 81-110. 2000 .

SHIROMA, E. O. ; MORAES, M. C. M.; EVANGELISTA, O. Ensino superior em tempos de adesão pragmática. In: MORAES, M. C. M. et al. (Org.). Iluminismo às avessas. Produção de conhecimento e políticas de formação docente. Rio de Janeiro: DP\&A/CNPQ, 2003, p. 129-149.

STOER, S. R.; MAGALHÃES, A. A diferença somos nós. A gestão da mudança social e as políticas educativas e sociais. Porto: Afrontamento, 2005.

VICENTE, L. Sorbonne, Bolonha, Praga...Notas para uma leitura crítica. Vértice, n. 112, p. 72-92, 2003.

WONG, B. Ministério do Ensino Superior quer legislar Bolonha até Março. Jornal Público, edição de 24 de Janeiro de 2006(a), p. 22.

. Bolonha? 'A minha mãe é que anda mais a par disso'. Jornal Público, edição de 24

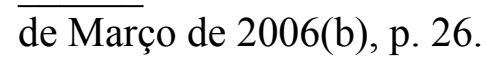

. Ensino superior. Harmonização a nível europeu já está em marcha. O que mudou na vida das escolas um ano depois de Bolonha. Jornal Público, edição de 24 de Março de 2007.

. Instituições entregam dossiers de Bolonha sem conhecer regras. Jornal Público, edição de 31 de Março de 2006, p. 26. 


\section{DOCUMENTOS ELECTRÓNICOS}

Conference Programme. Conference of European Ministers Responsible for Higher Education. Bergen, 19-20 de Maio de 2005, Acesso em: 12 de Maio de 2005.

Copenhagen Declaration. Declaration of the European Ministers of Vocational Education and Training, and the European Commission, Convened in Copenhagen on 29 and 30 November 2002, on Enhanced European Cooperation in Vocational Education and Training. Disponível em: http://europa.eu.int/comm/education/copenhagen/ copenhagendeclarationen.pdf. Acesso em: Jan. 2006.

CUSSÓ, R.; D'AMICO, S. From development comparatism to globalization comparativism: towards normative international education statistics. Comparative Education, 2005, vol. 41, $\mathrm{n}^{\mathrm{o}}$ 1. Disponível em: http://ugle.svf.uib.no/sofweb1/filer/1284.pdf. Acesso em: mai. 2005.

Declaração de Bolonha . Joint Declaration of the European Ministers of Education, Convened in Bologna on the 19th of June 1999. Disponível em:

http://www.europa.eu.int/comm/education/bologna en.html. Acesso em: 4 Setembro de 2003.

FEJES, A. The Bologna Process - governing higher education in Europe trough standardisation. Comunicação apresentada à terceira conferência sobre Knowledge and Politics - the Bologna Process and the Shaping of the Future Knowledge Societies, Universidade de Bergen, 18-20 de Maio de 2005, Noruega. Disponível em: http://ugle.svf.uib.no/svfweb1/filer/1288.pdf. Acesso em: 31 de Maio de 2005.

MATHISEN, G. Chasing quality. WTO and UNESCO; multilaterals at work. Comunicação apresentada à terceira conferência sobre Knowledge and Politics - the Bologna Process and the Shaping of the Future Knowledge Societies, Universidade de Bergen, 18-20 de Maio de 2005, Noruega. Disponível em: http://ugle.svf.uib.no/svfweb1/filer/1288.pdf. Acesso em: 31 de Maio de 2005.

NEAVE, G. Mr Prometeus - unbound, shackled or released on parole? Being certain Adumbrations on the Marvellously Changing Relationship between Government and Higher Education in Western Europe. Disponível em: http://www.ccla.pt/brainstorms/ release1.0/flash.htm. Acesso em: 1 de Outubro de 2004.

OCDE. Internationalisation of Higher Education, Policy Brief de Agosto de 2004.

Disponível em: http://oecd.org.dataoecd/6/27/33730442.pdf, Acesso em: 13 de Dezembro de 2004.

Realising the European Higher Education Area Comuniqué of the Conference of Ministers responsible for Higher Education in Berlin on 19 September 2003. Disponível em: http://www.bologna-berlin2003.de/en/aktuel/index.htm. Acesso em: 29 de Dezembro de 2003.

The European Higher Education Area - Achieving the Goals. Disponível em: http://www.bologna bergen.no/Docs/00-Main_doc/050520_Bergen_Comunique.pdf. Acesso em: 20 de Maio de 2005. 
Towards the European Higher Education Area, Comuniqué of the Meeting of Europen Ministers in Charge of Higuer Education in Prague on May 19th 2001. Disponível em: http://www.europa.eu.int/comm/education/bologna_en.html. Acesso em: 16 de Abril de 2003.

Work Programme 2003-2005 for the Bologna Follow-Up Group, Disponível em:

http://bologna-bergen2005.no/B/BFUG_Meetings/040309Dublin/BFUG2_3.pdf. Acesso em: 22 de Março de 2005.

Normativos legais

Despacho $n^{\circ}$ 484/2006 (2a série), Diário da República - II série de 9 de Janeiro de 2006.

Decreto-lei no 74/2006, Diário da República - I série-A de 24 de Março de 2006.

Lei n. ${ }^{\circ}$ 62/2007 de 10 de Setembro 